\title{
VOZES AO ALTO. CANTAR EM CORO EM PORTUGAL (1880-2014): PROTAGONISTAS, CONTEXTOS E PERCURSOS,
}

por MARIa do Rosário Pestana (coordenação). Lisboa: Movimento Patrimonial pela Música Portuguesa, 2015, 506 páginas. ISBN: 978-989-98562-2-6.

\section{UMA OBRA QUE FALTAVA}

Impossível seria não acolher com agrado uma obra que finalmente trouxesse uma síntese atualizada e documentada das contribuições que, nas últimas três décadas anos, têm procurado elucidar sobre as práticas de canto em coro em Portugal.

O livro em apreço insere-se no projeto « «A música no meio»: O canto em coro no contexto do orfeonismo (1880-2012)», apoiado pela Fundação para a Ciência e Tecnologia, a agência portuguesa para o financiamento da investigação, e inscrito na Universidade de Aveiro. O projeto organizou também o congresso internacional «Música e imaginários partilhados: nacionalismos, comunidades e canto em coro». Este congresso de Aveiro reuniu, em 2014, contribuições de investigadores de todo o mundo; as suas atas, com uma vertente mais transnacional e com assentamento no campo musicológico, podem ser consultadas em volume próprio. ${ }^{1}$ Vozes ao alto culmina uma pesquisa conjunta, mostrando uma vertente do projeto tendencialmente circunscritas a questões históricas e educativas a uma escala nacional. O volume é interdisciplinar, salientando-se as perspetivas da «etnomusicologia, musicologia, sociologia, antropologia, estudos culturais, estudos em performance, ciências da comunicação e

\footnotetext{
${ }^{1}$ Maria do Rosário Pestana y Helena Marinho (eds.), Music and shared imaginaries: nationalisms, communities, and choral singing. Proceedings (Lisboa: Edições Ex-Libris, 2014). http://musicanomeio. web.ua.pt/sites/default/files/Music.pdf (consultado em 13-06-2016).
} 
arquivística» (p. 2). Reconhece-se aqui também a sua contribuição para a historiografia da música e para a história da educação artística.

Retoma, no essencial, a problemática basilar do projeto matriz, que se prendia com o estudo do canto em coro amador, mas com enfoque na «instituição orfeão, um tipo de sociedade coral que emergiu com o fim do Antigo Regime, no final do século XIX, no seio da sociedade civil, nos primeiros centros urbanos portugueses», e nas "associações que promoveram a prática coral fora do contexto da igreja, do teatro ou da escola» (p. 1). Um dos grandes méritos deste trabalho passa por demonstrar, de modo sistemático, que um estudo aprofundado sobre o canto orfeónico remete para o lugar-entre, extrapolando dicotomias com as de «profissional» e «amador» (pp. 1, 7), e demandado abordagens teóricas metodológicas e conceptuais cada vez mais sofisticadas, capazes de dar conta das dinâmicas sociais entre os atores individuais, as ações grupais e os movimentos estéticos, políticos e sociais, implicados nesta prática musical.

A extensa introdução, da responsabilidade da coordenadora, sintetiza as contribuições, apresentando uma panorâmica de conceitos e abordagens que permite constituir ou, pelo menos, apontar os deslocamentos teóricos e empíricos trazidos, ao mesmo tempo que contextualiza a obra no quadro de uma pertinente revisão da literatura. Acede-se, assim, a uma resenha sobre o canto coral em Portugal com olhares sobre as dimensões estéticas, sociais e políticas, e também com forte pendor historiográfico.

A mais recente enciclopédia da música portuguesa, dirigida por Salwa Castelo-Branco, extremamente informada no que respeita a individualidades, divulga alguns artigos de fundo, sob temas que encontramos agora mais desenvolvidos em Vozes ao alto. Nessa obra de referência, apareciam verbetes sobre a definição geral de coro e de orfeão e avançava-se para uma história bastante resumida do coro amador em Portugal. Mas, excetuando as referências realizadas a Coros no interior de biografias de personalidades, apenas eram individualizadas as referências ao Coro Gulbenkian, ao Orfeão Académico de Coimbra ou ao Orpheon Portuense. ${ }^{2} \mathrm{O}$ volume publicado por Pestana acaba por permitir também a am-

\footnotetext{
${ }^{2}$ Salwa Castelo-Branco, Enciclopédia da Música em Portugal no Século XX, 4 vols (Lisboa: Temas \& Debates/ Círculo de Leitores, 2010).
} 
pliação destas referências, desta feita sobre individualidades e agrupamentos especificamente dedicados ao canto em coro.

Não pode, todavia, atribuir-se qualquer falha pelo facto de haver temas ou instituição que não tenham sido contemplados, uma vez que a obra não se reclama nem totalizante, nem enciclopédica —embora na prática possa funcionar como tal. Com efeito, até à publicação de Vozes ao alto, não existia uma obra de estudo ou consulta capaz de dar conta deste tema. Existiam, isso sim, uma série de monografias académicas ou de inspiração local e associativa, sem que se tivesse ainda realizado um esforço sistemático da compreensão do movimento de divulgação e pesquisa que se tinha vindo a realizar. Percebe-se agora melhor a falta que esta coletânea fazia no nosso panorama investigativo. Porém, tender-se-á sempre a demandar mais estudos monográficos e uma síntese cada vez mais abrangente, até que se possa, efetivamente, tomar pulso a este fenómeno cultural. Deste modo, o livro preenche uma lacuna, mas logo abre outra, ao trazer ao leitor o desejo de uma obra de ainda maior envergadura.

\section{CANTO EM CORO E PODER: NAS UTOPIAS, NAS IDEOLOGIAS E NAS COMUNIDADES}

De modo muito sucinto, a obra apresenta uma configuração tradicional no conteúdo, sendo a sua qualidade ressaltada pela edição gráfica, que individualiza cada um dos artigos. Inicia-se com um preâmbulo, onde se explicita brevemente o projeto em que o livro se insere, e uma larga introdução de síntese problematizante, ambas da autoria da coordenadora. $\mathrm{O}$ corpo de texto divide-se em três partes, cada uma delas - a meu ver - abordando um prisma da relação entre música e formas de poder. Ao invés de uma conclusão, optou-se por usar um epílogo que procura desconstruir alguns mitos do canto comunitário e demandar novas linhas de pesquisa. Encerra em beleza com a partitura de «O Palácio», para coro misto, do compositor António Chagas Rosa, criada para a abertura da conferência «Música e imaginários partilhados», acima referida. Contém ainda uma secção de notas biográficas dos dezassete colabores, índice remissivo e lista de figuras. 
As três partes principais são dedicadas, cada uma delas, a um tema-problema do canto em coro e as suas relações com o poder, aqui entendido não apenas como político, mas também como cívico e interpessoal. Instala-se assim uma divisória entre os estudos que se atêm a utopias do progresso e cidadania, às formas de atrito e instrumentalização durante o regime do Estado Novo, e aos estudos de caso sobre a prática musical propriamente dita. As duas primeiras partes são, assim, de vocação histórica, ao passo que a parte final se reveste de caráter mais etnometodológico e antropológico, com uma perspetiva sobre o presente da performance e dos problemas educativos e societais suscitados pela prática do canto em coro.

Na primeira parte, "O canto orfeónico: utopias de progresso e ações exemplares», contam-se cinco artigos. Maria José Artiaga, uma autora de referência no país para este tema quase inexplorado da educação musical, fornece um retrato ilustrativo sobre «O início do canto em coro no contexto educativo português no século XIX: ideias e práticas». O contributo seguinte, de Maria Nagore Ferrer, "Música coral y identidades en Espãna (1880-1939») faz sentido aqui, ao evidenciar, de um modo sintético e impressivo, a relação entre o canto em coro e a construção das chamadas "comunidades imaginadas»: Catalunha e Valência, Galiza, País Basco, Astúrias, Leão, Castela e Cantábria são comunidades no sentido estrito, sendo de sublinhar que nessas zonas da Norte e Este da península se concentravam a maior parte das sociedades corais (p. 76). Num sentido lato entende-se a construção de Espanha como Estado Nacional, tendo em conta as suas clivagem político-ideológicas. Além do seu valor intrínseco, esta narrativa contém a potência comparativa, nomeadamente ao referenciar um dos agrupamentos mais citados em Portugal, o Orfeão Donostiarra. Segue-se um capítulo sobre o repertório cantado em «O período coral do (1881-1909) da Sociedade Orpheon Portuense (1881-2008): textos e contextos», da autoria de Henrique Luís Gomes de Araújo, um membro histórico desta instituição centenária, e o coordenador de uma obra monográfica. ${ }^{3}$ Na sequência, o artigo de Rui Marques, dedicado ao mais antigo agrupamento português, «O Orfeão Académico de Coimbra (1880-1912): nacionalismo e cosmopolitismo no começo de

\footnotetext{
${ }^{3}$ A Sociedade Orpheon Portuense, tradição e inovação (Porto: Universidade Católica Portuguesa, 2014).
} 
uma nova era», coloca a intervenção dos modelos de cidadania, trazidos em particular pelo maestro António Joyce (1888-1964). Estes capítulos referem-se, assim, aos coros que, no panorama português são os mais longevos e também os que têm sido alvo de um maior número de estudos. Por contraste, o capítulo que fecha esta primeira parte refere-se ao contexto do orfeão operário, ainda pouco estudado em Portugal. «Do Orfeão Martins Rosa ao Orfeão da Fábrica da Vista Alegre», um centro de produção de porcelanas que ainda hoje existe e é uma marca emblemática da cultura nacional, oferece uma panorâmica histórica que vem desde 1931. Pedro Rocha apresenta uma análise vívida da história do orfeão, entretecida com a descrição e análise dos vários componentes (membros, repertório, atividades e dinâmicas extra-corais, etc.).

Na segunda parte, "Hegemonia e resistência: institucionalização de práticas corais durante o regime do Estado Novo", Vozes ao alto penetra numa sequência com cronologias mais curtas e centradas na problemática de música e do poder político no seu sentido mais cru, tanto na perspetiva da resistência ao poder, quanto da sua imagética e consagração. A abertura foi deixada a Teresa Cascudo, autora de diversas obras de referência sobre o compositor Fernando Lopes-Graça (1906-1994) e responsável pela catalogação da sua obra. Em «Viver cantando a corrente que nos arrasta: Fernando Lopes-Graça e a música para coro entre 1945 e 1952», oferece uma "leitura sistemática das fontes documentais atualmente ao nosso dispor»e, em suma, uma problematização sobre a prática musical de resistência centrada neste músico comunista.

Cascudo analisa uma das composições do ciclo canções heroicas, «Jornada», com letra de José Gomes Ferreira, a mesma que tem por refrão «Vozes ao alto! Vozes ao alto!». Essa foi uma das canções que, depois de ter sido cantada na clandestinidade (por presos políticos ou em extra de concertos) ganhou popularidade após a mudança de regime em 1974. Este verso parece ter dado origem ao feliz título a esta obra, que casa na perfeição com a fotografia do coro da Academia de Amadores de Música, que tinha por diretor o próprio Lopes-Graça, e aparece retratado em Beja, 1978, sob direção do maestro-adjunto José Robert. Permita-se aqui o parêntesis, mas sendo uma relação clara e mesmo automática para um nativo, dificilmente será inteligível sem uma explicitação para um leitor estrangeiro. 
Voltando à sequência, Manuel Deniz Silva, também uma referência para os estudos desta época, observa «A música coral como utopia disciplinadora em A gente canta como na aldeia (1955) de Mário Sampaio Ribeiro» (1898-1966). Embora se trate de um romance, a análise dessa obra divulgada em plena época das campanhas de alfabetização, permite reconstituir a complexidade e dinâmica do pensamento de um autor que enquanto compositor, e contra as suas posições teóricas, acabou por realizar a harmonização de diversas canções populares, e, em funções políticas propôs a instrumentalização da música para finalidades de manutenção de ordem e moral, subalternizando a difusão da educação musical em prol da educação através da música (p. 218). "A Sociedade Coral Portuguesa: um projeto artístico singular no panorama musical português», trata de uma instituição estreada no âmbito das Comemorações dos Centenários, um acontecimento oficial que em 1940 visou legitimar o Estado Novo à luz da história das conquistas e descobrimentos. André Vaz Pereira conclui que esta apenas pode ser suportada durante o tempo em que houve subvenção pública, de 1940 a 1947, devendo-se também a sua curta vigência à "concorrência» com a Sociedade Coral Duarte Lobo, outro agrupamento de música erudita que existia desde 1928. Ainda na senda da hegemonia do poder, Helena Marinho em «As viagens a África do Orfeão Universitário do Porto entre 1956 e 1962: contextos, repertórios, rituais» debruça-se sobre um aspeto específico dessa formação cuja história remonta a 1912. Conclui que, tanto a interação como o ritual, «nos espetáculos do OUP, funcionavam como lugares de construção e transferência de identidade», tendo aqui em conta que se tratava de uma «identidade que se apresentava e se queria genuinamente portuguesa» (p. 274). Finalmente, em "A criação do Centro de Estudos Gregorianos e a sua atividade coral no universo da música sacra», Idalete Giga traça um historial de uma das seis escolas de música públicas do país (desde 1973), tendo em conta a sua matriz original como escola de música sacra, fundada em 1953 pelo impulso de Júlia d'Almendra (1904-1922), com três coros: Schola, Palestrina e Infantil Ward.

A terceira parte «Práticas de cantar em coro: estudos de caso» compõe-se de quatro artigos. Jorge Castro Ribeiro examina «Coros madeirenses: sociabilidade, representação insular e participação musical», a partir de uma reflexão etnomusicológica que se completa com uma pequena resenha histórica desde o século XIX, onde salienta os principais agrupa- 
mentos, até ao presente. «Música sacra em Portugal nos séculos XX e XXI: um tesouro a descobrir» é um modo elegante de Paulo Bernardino colocar o seu argumento: a ausência da música sacra das páginas de história da música portuguesa, a falta de perspetiva de uma carreira para os jovens formados pelo curso de Música Sacra, e, paradoxalmente, o seu desaparecimento até da própria Igreja. A maestrina Aoife Hiney contribuiu com uma reflexão sobre «Os desafios dos maestros de coros voluntários em Aveiro» sobre a sua pesquisa junto de coros (que não os dirigidos por si). Uma parte central dos desafios identificados prendem-se, antes de mais nada com a literacia musical dos membros dos coros estudados, desigual, mas geralmente pouca ou nenhuma. A falta de literacia obriga os maestros a ensinar de acordo com a técnica do rote learning, em que se vai ensinando por repetição, cada uma das vozes, por partes (p. 404). Sublinhe-se a representação do coro, para os seus membros, "como um lugar vazio de possibilidades no âmbito do aumento das competências em literacia musical»(p. 424), como uma das evidências mais impactantes deste estudo e no conjunto da obra. Por fim, Ivone Carvalho caracteriza «A prática coral no concelho de Viana do Castelo: um estudo de caso». Destaca-se a variável idade, o que revela a preocupação mais constante ao longo da caracterização realizada: a de verificar as possibilidades existentes para os coros comunitários desta região, tendo em conta tratar-se de grupos essencialmente séniores. São assim enunciadas desde possibilidades materiais a capacidades e habilidades de aprendizagem, sendo fortemente sugerida a otimização do recurso à memória, como forma de animação do coro e dos seus membros.

O epílogo preenche-se com as palavras pronunciadas por Ruth Finnegan na comunicação apresentada na conferência de 2014 em Aveiro, onde se reconhece à emérita socióloga e antropóloga a inspiração do projeto "A música no meio». Com efeito, a sua obra The Hidden Musicians, sobre uma pequena aldeia inglesa, com edição original em 1989, permanece como referência nesta matéria. Descartando-se como autoridade, mas justamente abraçando as possibilidades trazidas pela eminência, discutiu alguns dos implícitos subjacentes aos estudos sobre o canto em coro. Por exemplo, grande parte da pesquisa que envolve os coros comunitários assenta na ideia de que a música une as pessoas, até porque «as afasta das divisões individualistas do quotidiano e as leva para fora do tempo e do espaço, para além delas mesmas» (p. 471). É todavia possível 
contradizer esta ideia e afirmar que «a produção pode servir tanto para dividir como para promover a harmonia» (p. 474). Mais do que provocatória, esta abordagem tem em conta as múltiplas dimensões da ação dos atores sociais. Finnegan coloca em cima da mesa várias pistas de pesquisa, que ilustra com a sua experiência, uma delas relacionada com uma linha de pesquisa da música do dia-a-dia, que considera os efeitos da música em cada pessoa que canta e/ou que escuta, bem como uma outra que se prende com a dimensão biológica dos seres humanos. Talvez a fundir ambas as pistas, chamando a sua vertente de antropóloga, sublinha a importância da reminiscência da música na consciência do ser.

\section{APPORTS E POSSIBILIDADES PARA UMA HISTÓRIA DA EDUCAÇÃO}

Inúmeros destes artigos contêm já uma preocupação com a perspetiva histórica e com as questões educativas. Em particular, pelo que se lê na introdução e no artigo dedicado ao início do canto em coro no contexto educativo, permitir-se-ia abrir um novo capítulo na história da educação dedicado ao canto orfeónico. O canto escolar aparece bem identificado por Artiaga como sendo uma modalidade diferenciada, suportada por legislação, políticas educativas, repertório específico e adaptado, manuais, professores com formação ou pelo menos atuação especializada. São mapeadas escolas de diferentes tipologias (escola primária, o orfanato estatal Real Casa Pia de Lisboa, as escolas municipais de Lisboa, e os liceus). Recorde-se que o canto coletivo foi implementado escolarmente por razões de natureza higiénica (do corpo e da alma). As resenhas de Pestana e de Artiaga, aliadas a uma série de informações que se sucedem fragmentariamente nos restantes artigos, inspiram uma série de indagações que talvez possam ser realizadas no futuro.

Com efeito, seria relevante no contexto investigativo aduzir novas interrogações numa dinâmica de história da educação. Ocorre aprofundar a relação entre os objetivos políticos e as pessoas que, em determinados enquadramentos grupais, corporizam estes movimentos, e como se têm movimentado as redes de atores sociais que suportam estas práticas, desde promotores, ideólogos, maestros, membros, líderes culturais e associativos, mas também as dinâmicas locais e familiares de inserção. Apetece também continuar a pesquisar sobre a intertextualidade de métodos 
usados na prática do ensino coral, tendo em conta, justamente, a baixa literacia musical portuguesa, e a sua genealogia em termos históricos. $\mathrm{O}$ canto escolar para o ensino infantil, primário, secundário, e agrupamentos locais foi, em algum momento, teorizado ao nível dos ideólogos de um regime político, numa revisão crítica abrangente que permanece por explorar. Importaria ainda tratar a instituição do orfeão académico, que tem a potencialidade de acompanhar a passagem para a vida adulta dos alunos e viu os seus objetivos discutidos e aplicados, mas nunca teorizados. Sendo a implementação de grupos de canto em coro um fenómeno nacional de caraterísticas globais (p. 29), importaria ainda adentrar mais por uma perspetiva de história da educação comparativa, em particular com o espaço ibérico e lusófono.

Por tudo quanto Vozes ao alto trouxe, mas também pelo que não houve oportunidade de afrontar, é uma obra a difundir... e continuar.

Ana Luísa Fernandes Paz

Universidade de Lisboa apaz@campus.ul.pt 